\title{
Risk factors analysis of HPS patients with acute Stanford A aortic dissection
}

Qiuxia Xie ( $D$ Qiuxia_Xie123@126.com )

Sun Yat-Sen University https://orcid.org/0000-0002-6501-6738

Haoling Qin

Sun Yat-Sen University

Ling Lin

Universiteit Leiden

Jian Guan

Sun Yat-Sen University

Xuhui Zhou

Sun Yat-Sen University

Research article

Keywords: Stanford A aortic dissection; HPS; CCl; aortic dissection; effusion/blood

Posted Date: September 11th, 2019

DOI: https://doi.org/10.21203/rs.2.14309/v1

License: (c) (i) This work is licensed under a Creative Commons Attribution 4.0 International License.

Read Full License 


\section{Abstract}

Background: $A A D$ refers to the blood flow into the middle membrane through the intimal rupture of the aorta. HPS is a common complication of Stanford-A AAD. The risk factors of HPS are remaining unclear Methods: In this study, we have probed the potential risk factors of hepatopulmonary syndrome (HPS) patients with acute Stanford A aortic dissection. 18 HPS patients with acute Stanford A aortic dissection were selected as case group. 36 Normal people were considerate as control group. Demographic data, treatment methods, $A D$ related disease history, clinical symptoms and Charlson comorbidity index (CCI) values of each patient were collected. Meanwhile, the values of maximum diameter of ascending aorta $(\mathrm{mm})$, aortic dissection range, and main branch of aorta, pleural effusion/blood, and pericardial effusion/blood were measured by two experienced cardiovascular radiological physicians. Univariate and multivariate conditional logistic regression analysis were used in this study. Results: $\mathrm{CCl}$ value and the branches of the brachiocephalus in case group were significant higher than that in control group $(\mathrm{p}<0.05)$. Univariate conditional logistic regression analysis showed $\mathrm{CCl}$ and branches of the brachiocephalus were associated with HPS. Multivariate conditional logistic regression analysis suggested that branches of the brachiocephalus was an independent risk factor for HPS (OR=7.02, $95 \% \mathrm{Cl}=1.28-38.62, \mathrm{p}=0.025)$. Conclusions: Branches of the brachiocephalus were an independent risk factor for HPS.

\section{Background}

Acute aortic syndrome (AAS) is a serious, life-threatening aortic syndrome, which mainly includes acute aortic dissection (AAD), aortic penetrating ulcer, intra-aortic hematoma, and traumatic aortic injury [1-2]. $A A D$ refers to the blood flow into the middle membrane through the intimal rupture of the aorta, which result in the separation of the inner and outer membranes. The incidence rate of $A A D$ in population is about 2.6-3.5/100000/year. ${ }^{[3]}$ Meanwhile, about $85 \%-95 \%$ of AAS patients could be diagnosed with AAD [3]. AAD has various clinical features, including acute onset, rapid progress, complications, and high mortality. About $20 \%$ of patients die within one hour of onset [4-5]. Current medical anatomical classification methods for AAD include Debakey typing and Stanford type. The Stanford typing method is closely related to the treatment method. Therefore, it is more commonly used [6]. The Stanford typing method divides AAD into Stanford-A and Stanford-B. Stanford-A accounts for approximately $75 \%$ of AAD. Meanwhile, the diagnosis of AAD mainly depends on imaging examination. CT examination as one of the most important imaging method has been widely used in the diagnosis of AAD [6, 7]. Multi-detector computed tomography (MDCT) has high imaging speed and high resolution. Computed tomographic angiography (CTA) has high sensitivity and specificity for AAD diagnosis. Sensitivity and specificity of both methods for AAS diagnosis are close to 100\% [8-10]. The mechanism of AAD has not been clarified. Studies have shown that genetic or metabolic abnormalities may cause degeneration and/or cystic necrosis of collagen fibers and elastic fibers in the aortic wall, which would further result in the separation of the aortic intima and adventitia in the proximal and/or distal aorta [11-13]. Meanwhile, studies have shown that multiple acquired factors can affect the occurrence and development of AAD. These factors 
include Hypertension, trauma, infection, iatrogenic injury, dyslipidemia, atherosclerosis, pregnancy, smoking, stroke, drugs, chronic renal insufficiency, autoimmune diseases, chronic obstructive pulmonary disease, etc [6]. Approximately $77 \%$ of AAD patients are associated with hypertension. Therefore, hypertension is considered to be the most important risk factor [12]. Hypertension can lead to a variety of emergency reactions, including increased arterial wall pressure, release of matrix metalloproteinases and various cytokines, and excessive degradation of extracellular matrix. Therefore, it ultimately leads to intimal injury and aortic wall degeneration [13].

Hemorrhagic pulmonary sheath (HPS) is a common connective tissue with sheath structure in which the blood of the aortic dissection breaks into the central pulmonary artery and the aortic root. Previous reports have suggested that HPS is a common complication of Stanford-A AAD [14]. Due to the poor evidences, previous studies used different terms to describe this complication such as intrahepatic hematoma $[15,16]$, pulmonary sphincter hematoma [17], blood infiltration of the aorta and pulmonary vascular adventitia [18], and hemorrhage along the pulmonary sheath [19], extraluminal perivascular hemorrhage [20], and hemorrhage along the pulmonary artery [21-23]. The results of HPS in chest radiographs examination varies according to the range of bleeding (normal to double lung flaky infiltration) [24-25]. Sueyoshi et al. retrospectively analyzed 232 cases of Stanford-A AD patients with extravasation of blood along the pulmonary artery [23]. The results suggested that 21 cases $(9.1 \%)$ of extravasated blood along the pulmonary artery, double-chamber aortic dissection and blood inthe alveoli are associated with poor prognosis. The authors speculate that the poor prognosis is due to high pressure around the pulmonary artery and massive exudation of blood around the pulmonary artery, which leads to alveolar hemorrhage and reduced pulmonary circulation [23].

In word wild, there are few studies about the incidence of HPS. More importantly, the risk factors of HPS are remaining unclear. In this study, we have carried out case-control study. Traditional AAD risk factors (age, gender, hypertension, etc.), CCl and MDCT characteristics (upper aortic maximal diameter, aortic dissection range, main aortic vascular involvement, pleural effusion/blood, pericardium) have been included to study the relationships with HPS in this study. Risk factors for HPS have been screened. The information in this study would be helpful for future detection and treatment of HPS.

\section{Methods}

\section{Group}

This study retrospectively analysis 188 patients who were diagnosed with acute Stanford-A AD by chest and abdomen CT scan and CTA examination in The Eighth Affiliated Hospital of Sun Yat-sen University between January 2011 and January 2016. 18 HPS patients were finally included based on the results of CT scan image and CTA image. 36 acute Stanford-A aortic dissection without HPS were included and marked as the control group. Patients in control group should satisfy the following criterions: age difference in \pm 5 years, same gender, and paired with HPS patients according to the similar visiting time. Exclusion criterions were complied with the following conditions: patients with chronic aortic dissection; 
patients with aortic dissection stenting; patients with simple aortic aneurysm; patients with severe lesions (trauma); poor quality of CT images.

\section{Clinical information}

The data of the control group and the case group were collected: 1) baseline data (age, gender), 2) AD related diseases information (history of hypertension, history of diabetes, history of connective tissue disease, history of chronic lung disease, history of chronic cardiovascular disease, chronic History of kidney disease, history of hyperlipidemia. 3) Clinical symptoms and clinical signs associated with AD: chest and back pain, syncope, sudden dyspnea, cough, hemoptysis or blood stasis, nervous system symptoms, shortness of breath, tachycardia, decreased blood pressure, myocardial infarction or infarction, heart failure, renal failure Abnormal liver function. 4) Treatment information (surgical treatment or conservative treatment). Charlson comorbidity index (CCl) was calculated based on the information of AD related diseases. Table S1 showed the detailed information for scoring criteria.

\section{MDCT scanning method and CT image analysis}

A 64-slice spiral CT (Aquilion TSX-101A, Canon Medical Systems (China) Co., Ltd.) was used to perform a three-phase (plain, arterial, venous) scan. Patient was placed in a supine position. Scanning was ranged from chest inlet to groin level. Scanning parameters were listed as following: tube voltage $120 \mathrm{kV}$, automatic tube current, volume data layer thickness $1 \mathrm{~mm}$, layer spacing $0.8 \mathrm{~mm}$, rotation time $0.5 \mathrm{~s} /$ Rot, pitch 0.828 , collimator width $64 \times 0.5 \mathrm{~mm}$. The matrix was $512 \times 512$. The window width was set to $400 \mathrm{HU}$, the window level was set to $40 \mathrm{HU}$. The soft tissue reconstruction algorithm was used. The thick layer transverse image reconstruction layer had a thickness of $3 \mathrm{~mm}$ and a layer spacing of $3 \mathrm{~mm}$. After flat scan, a high-pressure syringe (meDRAD) was used to inject $80 \mathrm{ml}$ iopromide (300 mg / $\mathrm{ml}$, Bayer HealthCare Co., Ltd.) through the right elbow vein $(3.5 \mathrm{ml} / \mathrm{s})$. After the injection, $40 \mathrm{ml}$ of physiological saline was added at the same rate to perform a flushing. The contrast agent automatic tracking technology is used to trigger the arterial phase scan. Firstly, a layer is pre-scanned on the diaphragm plane as the detection plane. The region of the aortic cavity is placed to trigger the region of interest to monitor the change of CT value in the aortic cavity. The scan interval was $1 \mathrm{~s}$. The auto-trigger CT threshold was set to $150 \mathrm{HU}$. When the CT value threshold of the interested region reached $150 \mathrm{HU}$, the delay $6 s$ automatically started scanning to acquire the arterial phase image. The venous phase was scanned 65 seconds after the contrast injection. The scanning range and scanning parameters were the same as those of the arterial phase. Acute Stanford-A aortic dissection refers to dissection that separates the intima of the ascending aorta from the adventitia [26]. Meanwhile, the onset time is $<14$ days [27]. The HPS diagnostic criteria were listed as following: 1) The CT scan image had a circular, crescentshaped high-density shadow around the main pulmonary artery and/or pulmonary artery trunk or branch vessel wall. 2) Enhanced CT images showed that ring-shaped, crescent-shaped shadows were lowdensity soft tissue shadows without enhancement. Aortic branch vascular involvement is defined as following: 1) The torn inner membrane entered into the intima of the branch vessel. The branch vessel was supplied by the true cavity and the false lumen. 2) The inner membrane of the branch vessel was 
completely torn. The blood supply of the branch vessel was completely from the false lumen. 3) The tearing inner membrane did not enter the branch vessel. The blood supply of the branch vessel was derived from true lumen with branch vessels. Any combination of dissection involving the brachiocephalic or left common carotid artery or left subclavian artery or brachiocephalic trunk, left subclavian artery, and left common carotid artery was defined as involvement of the brachial vascular branch. Any combination of dissection involving the celiac trunk or superior mesenteric artery or left or right renal artery or celiac trunk, superior mesenteric artery, left renal artery, and right renal artery was defined as abdominal branch vessel involvement. Chest or pericardial exudate CT value $>2 \mathrm{HU}$ was defined as chest or pericardial hemorrhage [28]. Definitions of hypertension, heart disease and dyslipidemia were referred to published guidelines $[29,30]$.

\section{Statistics}

Data analysis was performed using the SPSS 20.0 software package (Version 16, IBM, USA). Quantitative data with normal distribution was expressed as mean and standard deviation. Quantitative data with non-normal distribution was expressed by median and quartile. Categorical variables were described by percentage. Nonparametric rank sum test (Wilcoxon method) was used to compare the difference of the age the maximum diameter of the ascending aorta, and the $\mathrm{CCl}$ index between the case group and the control group. $\mathrm{X}^{2}$ test and Fisher exact probability method were used to calculate the differences of gender, $\mathrm{CCl}$, aortic dissection, aortic main branch vascular involvement, pleural effusion/blood, pericardial effusion/blood, hypertension, basic disease history, clinical symptoms, clinical Signs between the case group and the control group. Before the single factor logistic regression analysis, the variables were assigned (Table S2). The single factor regression analysis of 1:2 matching data was performed to calculate the P-values, odds ratio (OR) and odds ratio (OR) with $95 \% \mathrm{Cl}$ of age, gender, maximal diameter of ascending aorta, $\mathrm{CCl}$, extent of aortic dissection, involvement of major branches of the aorta, pleural effusion/blood, pericardial effusion/blood, hypertension. Before the multiple factor logistic regression analysis, the variables were assigned (Table S3). All factors with $p<0.1$ were included in a 1:2 matched multivariate conditional logistic regression analysis (fitting using Cox in survival analysis) to screen for risk factors for HPS. The odds (OR) was used as an approximate estimate of relative risk (RR). OR>1 was an independent factor, and $\mathrm{OR}<1$ is an independent protective factor. In single factor analysis test, the test level was $a=0.1$. In multivariate analysis test, the test level was $a=0.05$. All $p$ values represent the twosided probability.

\section{Results}

\section{Basic information}

In this study, a total of 188 patients, including 136 males (72.3\%) and 52 females (27.7\%) with acute Stanford-A AD were enrolled. The male to female ratio of total patients was 2.61:1, with an age range of 29-78 years and an average age of 59 years. There were 18 Stanford-A AD patients with HPS (case group), 13 males and 5 females. The male to female ratio of those patients was $2.6: 1$. The youngest was 
34 years old, and the oldest was 74 years old. The average age was 60.0 years. In the control group, members were matched with 2:1 for each HPS in case group (age $\leq 5$ year and the same gender). A total of 36 Stanford-A AD patients without HPS were included in the control group (26 males and 10 females, aged 29-78 years). The average age was 60.0 years old. There was no significant difference between the two groups ( $p>0.05$ ). The detailed information of patients was listed in Table 1 and Table 2. Moreover, we have compared the clinical information between control group and case group. In case group, there are 16 patients with hypertension (88.9\%), 3 patients with diabetes (16.7\%), 5 patients with chronic cardiovascular and cerebrovascular diseases (27.8\%), 2 patients with chronic lung disease $(11.1 \%), 4$ patients with moderate/severe of renal damage (22.2\%), 3 patients with connective tissue disease (16.7\%), 4 patients with peripheral vascular disease (22.2\%), 2 patients with mild liver damage $(11.1 \%)$, and one patient with tumor (5.6\%). Meanwhile, in control group, there are 34 patients with hypertension (94.4\%), 7 patients with diabetes (19.4\%), 12 patients with chronic cardiovascular and cerebrovascular diseases (33.3\%), 4 patients with chronic lung disease (11.1\%), 7 patients with severe renal damage (19.4\%), 4 patients with connective tissue disease (11.1\%), 7 patients with peripheral vascular disease (19.4\%), 3 patients with mild liver damage (8.3\%), and one patient with tumor history (2.8\%). There are no significant differences of hypertension, diabetes, chronic cardiovascular and cerebrovascular diseases, chronic lung disease, moderate/severe renal damage, connective tissue disease, peripheral vascular disease, mild liver damage, and tumor history between case group and control group ( $p>0.05)$. The detailed information has been presented in Table 3. In addition, we have further compared the Charlson comorbidity index (CCl) between two groups (Table 4). The results suggested that significant differences could be detected in both groups. In case group, the median $\mathrm{CCl}$ was 2 , the 25 th percentile was 1 ; the 75 th percentile was 3 . Meanwhile, in control group, he median $\mathrm{CCl}$ was 1 , the 25 th percentile was 1 ; the 75 th percentile was 1.5 (Table 4). There were statistical differences between the two groups in $\mathrm{CCl}$ index rank sum test and $\mathrm{CCl}$ score distribution chi-square test $(\mathrm{P}<0.05)$.

\section{Clinical information}

In this study, we have further compared the clinical symptoms, clinical signs, and MDCT features between two groups. In clinical symptoms study, we have compared six indexes, including chest pain, syncope, sudden breathing difficulty, hemoptysis or blood stasis, cough, and shortness of breath. There are no significant differences could be harvested $(P>0.05)$ (Table 5). In clinical signs study, we have studied tachycardia, blood pressure drop, myocardial infarction or ischemia, renal failure, and abnormal liver function. The results indicated that no differences of these six indexes could be detected between two groups ( $P>0.05$ ) (Table 6). In addition, we have studied the MDCT features between two groups (Table 7). The results revealed that no differences could be harvested in maximum diameter of ascending aorta $(\mathrm{mm})$, aortic dissection range, pleural effusion/blood, and pericardial effusion/blood. However, patients number related with branches of the brachiocephalus and ventral branch in case group was significant higher than that in control group $(\mathrm{P}<0.001)$. This result indicated that main branch of aorta was an important indicator for HPS patients in case group.

\section{Univariate conditional logistic regression analysis}


In this study, HPS was used as the dependent variable Y. Meanwhile, all other factors were used as the independent variable $X$. We performed the univariate conditional logistic regression analysis. The results suggested that no relationships could be retrieved between age, gender, hypertension and HPS $(P>0.05)$. However, $\mathrm{CCl}$ value in case group was lower than that in control group ( $\mathrm{P}=0.077)$. In addition, we had also calculate the relationship between other MDCT features and HPS. The results suggested that close relationships could only be detected between branches of the brachiocephalus and HPS (Table 8). The results mentioned above revealed that branches of the brachiocephalus and $\mathrm{CCl}$ value were two risk factors for HPS patients $(P<0.1)$.

\section{Multivariate conditional logistic regression analysis of HPS}

Based on the results of one-factor conditional logistic regression analysis, two variables with $p<0.1$ (CCl, branches of the brachiocephalus) were selected for multivariate logistic regression analysis. In order to avoid the false negative variables in multivariate analysis, $\mathrm{P}<0.1$ is considered to be related to HPS in one-factor conditional logistic regression analysis. Enter method was used in Multi-factor analysis. HPS was considerate as the dependent variable with a value of 1. Meanwhile, no HPS as the dependent variable assigned a value of 0 . Multi-factor conditional logistic regression analysis was carried out with

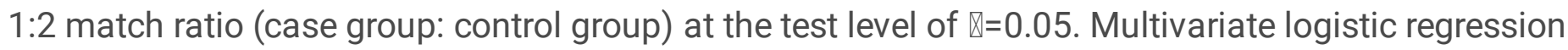
analysis of variable names and assignment instructions were listed in Table S3. The results suggested that branches of the brachiocephalus is an independent risk factor for HPS $(\mathrm{OR}=7.02,95 \% \mathrm{Cl}=1.28-38.62$, $\mathrm{p}=0.025)$ (Table 9$)$.

\section{Discussion}

In this study, the average age of 188 patients with acute Stanford-A AD was 59.0 years old. Although the onset age of acute $A D$ patients continued to increase with the aging of cardiovascular and cerebrovascular diseases and the aging of the population, the overall average age did not change much. The minimum age of this group of patients was 29 years old, and the maximum age was 78 years old (Average age $=59.0$ years). This is consistent with previous research results (64 \pm 14.1 years) [14]. Men are more likely to develop acute Stanford-A AD than women. In this study, Male to female ratio was 2.61:1. Males accounted for $72.3 \%$ of all patients. The international related acute AD database (IRAD) had reported that male acute Stanford-A AD patients accounted for $2 / 3$ of all acute Stanford-A AD patients. The results in this study were adopted with the literature reports [31]. It is speculated that high incidence rate of acute Stanford-A AD in male may be related to the bad habits of men such as smoking and drinking. Moreover, the clinical manifestations of patients with AAD are diverse. The literature reported that sudden chest pain or back pain (96\%) is the most common clinical symptom. The pain is continuous tearing, piercing, and knife cutting [32]. IRAD had studied a large sample size of AAD. The work (2932 cases) suggested that $85 \%$ of type A AAD clinical symptoms were chest pain [14]. In this study, 53 patients presented with chest pain $(98.1 \%)$, which was higher than the results reported, which may be caused by the small sample size. 
Multiple risk factors could be related with $A D$, including hypertension, trauma, dyslipidemia, iatrogenic injury, pregnancy, drugs, smoking, chronic renal insufficiency, chronic obstructive pulmonary disease, stroke, Marfan syndrome, etc $[5,6,14]$. Hypertension is the most important risk factor for $A D(77 \%$ of $A D$ patients with hypertension) [14]. Hypertension could lead to the changes in arterial hemodynamics, increased aortic insufficiency, and increased pressure in the arterial wall. Meanwhile, hypertension could promote the release of matrix metalloproteinases and inflammatory factors, causing excessive degradation of the extracellular matrix and altering the morphology of collagen fibers in the aortic wall. In this study, 52 patients $(96.3 \%)$ with Stanford-A AD had a history of hypertension, which was higher than the results of previous studies (70\%) [33]. We speculated that it could be related with the high incidence of hypertension in China. Meanwhile, a variety of underlying diseases can affect the development of AD, such as chronic renal insufficiency, chronic obstructive pulmonary disease, infectious vascular disease, and so on. In this study, the $\mathrm{CCl}$ score was used to reflect the overall underlying disease status. The $\mathrm{CCl}$ index of the case group was higher than that of the control group. There was a statistically significant difference between the two groups. Univariate analysis showed that the $\mathrm{CCI}$ score was one of the risk factors for HPS. However, CCl was not an independent risk factor for HPS.

The formation and development of aortic dissection is associated with increased arterial blood flow pressure. Muta et al. suggested that pulsating blood flow pressure could repeatedly act on the edge of $A D$ dissection, leading to AD expansion. Therefore, pulsating blood flow pressure is the most important factor affecting $A D$ [34]. In this study, $\mathrm{CCl}$ and branches of the brachiocephalus were included in multivariate analysis. Hypertension and the maximum diameter of the ascending aorta had not been included in this study. Previous work indicated that aortic wall tension was increased when the blood pressure was increased. The higher blood pressure of $A D$ patients, the more likely the aortic rupture occurs. However, in B-type AD patients, there are no evidences about the relationships between higher blood pressure and aortic rupture based on the multi-factor analysis [35]. Although hypertension was the cause of $A D$, it was not necessarily a risk factor for $A D$ rupture. We speculated that the fluctuations in blood pressure may have a greater impact on dissection rupture. Theoretically, the larger the aortic diameter, the more easily the aortic dissection was broken. However, the CT three-dimensional image study of $A D$ patients showed that the higher ratio of the maximum diameter of the aortic dissection to the length of the dissection, the greater risk of interlayer rupture [36]. In this study, no significant differences of the maximum diameter of the ascending aorta and the extent of involvement of the aortic dissection could be observed between case group and control group. The ratio of the maximum diameter of the aortic dissection to the length of the dissection had not been included in the study. Therefore, the correlation between the maximum diameter of the ascending aorta and HPS remains to be further studied.

The proportion of patients with involvement of branches of the brachiocephalus in case group was higher than that in control group (33.30\% for case group and $8.33 \%$ for control group). There was a statistically significant difference between the two groups $(\mathrm{p}<0.001)$. Univariate analysis showed $\mathrm{CCl}$ and branches of the brachiocephalus were closely related with HPS. Multivariate analysis showed that the involvement of branches of the brachiocephalus was an independent risk factor for HPS compared with the involvement 
of the ventral branch. Chang et al. showed that the degree of involvement of the main branches of the aorta can indirectly reflect the intracavitary tension and can indicate the risk of AD [37]. Involvement of the branches of the brachiocephalus may change the intra-orbital tension which could further cause increased blood flow impact and rupture of the ascending aorta. The results of this study showed that the risk of HPS involvement in the branches of the brachiocephalus was 7.02 times higher than that of the ventral branch, which may be due to the highest anatomical location of the brachiocephalic artery to ascending aorta. However, the relationships between the branches of the brachiocephalus number, brachiocephalic artery, left common carotid artery, left subclavian artery, and the HPS have not been fully demonstrated. Therefore, further study was necessary to conduct in related areas.

\section{Conclusions}

In summary, univariate analysis showed that $\mathrm{CCl}$ and branches of the brachiocephalus were the two major risk factors for HPS associated with acute Stanford-A AD. Meanwhile, multivariate analysis revealed that branches of the brachiocephalus were an independent risk factor for HPS.

\section{Abbreviations}

HPS: hepatopulmonary syndrome; CCl: Charlson comorbidity index; AAS: Acute aortic syndrome; AAD: acute aortic dissection; MDCT: Multi-detector computed tomography; CTA: Computed tomographic angiography;

\section{Declarations}

\section{Acknowledgements}

Thanks to all the patients involved in this experiment.

\section{Authors' contributions}

Qiuxia Xie: Study design, concept, writing; Haoling Qin and Ling Lin: Data collection, data analysis; Jian Guan, Xuhui Zhou: Corresponding author; Xuhui Zhou: Review the data organization; Jian Guan: Review the data management. All authors read and approved the final manuscript.

\section{Funding}

No applicable.

\section{Availability of data and materials}

The datasets generated during the present study are not publicly available, because detailed clinical information of each participant was included in these materials. 


\section{Ethics approval and consent to participate}

The study design was approved by the Ethics Committee of the Eighth Affiliated Hospital of Sun Yat-sen University (No: Sun Yat-sen-2011-KY-EAH-032; Aug. 8, 2011). Written informed consent was obtained from all participants. All procedures performed in studies involving human participants were in accordance with the ethical standards of the institutional and/or national research committee and with the 1964 Helsinki declaration and its later amendments or comparable ethical standards. Informed consent was obtained from all individual participants included in the study.

\section{Consent for publication}

Not applicable.

\section{Competing interests}

All authors declare no conflict of interest.

\section{References}

1. Carpenter SW, Kodolitsch YV, Debus ES, Wipper S, Tsilimparis N, Larena-Avellaneda A, Diener H, Kölbel T. Acute aortic syndromes: definition, prognosis and treatment options. J Cardiovasc Surg (Torino). 2014;55(2 Suppl 1):133-44

2. Sampson UK, Norman PE, Fowkes FG, Aboyans V, Yanna Song, Harrell FE Jr, Forouzanfar MH, Naghavi M, Denenberg JO, McDermott MM, Criqui MH, Mensah GA, Ezzati M, Murray C. Global and regional burden of aortic dissection and aneurysms: mortality trends in 21 world regions, 1990 to 2010. Glob Heart. 2014;9(1):171-180.e10

3. Tsai TT, Nienaber CA, Eagle KA. Acute aortic syndromes. Circulation. 2005;112(24):3802-13

4. Kawabori M, Kaneko T. Acute aortic syndrome: A systems approach to a time-critical disease. Best Pract Res Clin Anaesthesiol. 2006;30(3):271-81

5. Minegishi S, Watanabe H, Horita N, Shibata Y, Kaneko T, Ishigami T. The current evidence on diagnosis and treatment of acute aortic syndrome. J Thorac Dis. 2016;8(12):E1617-E1619

6. Hallinan JT, Anil G. Multi-detector computed tomography in the diagnosis and management of acute aortic syndromes. World J Radiol. 2014;6(6):355-65

7. Abbas A, Brown IW, Peebles CR, Harden SP, Shambrook JS. The role of multidetector-row CT in the diagnosis, classification and management of acute aortic syndrome. Br J Radiol. 2014;87(1042):20140354

8. Kapoor V, Ferris JV, Fuhrman CR. Intimomedial rupture: a new CT finding to distinguish true from false lumen in aortic dissection. AJR Am J Roentgenol. 2004;183(1):109-12

9. Valente T, Rossi G, Lassandro F, Marino M, Tortora G, Muto R, Scaglione M. MDCT in diagnosing acute aortic syndromes: reviewing common and less common CT findings. Radiol Med. 
2012;117(3):393-409

10. Chin AS, Fleischmann D. State-of-the-art computed tomography angiography of acute aortic syndrome. Semin Ultrasound CT MR. 2012;33(3):222-34

11. Fattori R, Cao P, De Rango P, Czerny M, Evangelista A, Nienaber C, Rousseau H, Schepens M. Interdisciplinary expert consensus document on management of type B aortic dissection. J Am Coll Cardiol. 2013;61(16):1661-78

12. Pape LA, Awais M, Woznicki EM, Suzuki T, Trimarchi S, Evangelista A, Myrmel T, Larsen M, Harris KM, Greason K, Di Eusanio M, Bossone E, Montgomery DG, Eagle KA, Nienaber CA, Isselbacher EM, O'Gara P. Presentation, Diagnosis, and Outcomes of Acute Aortic Dissection: 17-Year Trends From the International Registry of Acute Aortic Dissection. J Am Coll Cardiol. 2015;66(4):350-8

13. Yin H, Pickering JG. Cellular Senescence and Vascular Disease: Novel Routes to Better Understanding and Therapy. Can J Cardiol. 2016;32(5):612-23

14. Panicek DM, Ewing DK, Markarian B, Heitzman ER. Interstitial pulmonary hemorrhage from mediastinal hematoma secondary to aortic rupture. Radiology. 1987;162(1 Pt 1):165-6

15. Ratcliffe GE, Kirkpatrick ID. Stanford type A aortic dissection with pulmonary arterial intramural hematoma and pulmonary hemorrhage. J Cardiovasc Comput Tomogr. 2013;7(2):141-3

16. Miele V, Merola MG, Roncacci A, lanniello S. Pulmonary artery intramural hematoma associated with Stanford type B aortic dissection. J Cardiovasc Comput Tomogr. 2015;9(5):466-8

17. Pandit A, Panse PM, Gruden JF, Gotway MB. Pulmonary artery sheath haematoma with pulmonary arterial compression: a rare complication of type A aortic dissection mistaken for aortitis. Eur Heart J. 2013;34(44):3459

18. Guilmette J, Semionov A, Dennie C, Gahide G, Pressacco J, Fraser R, Cordeau MP, Chartrand-Lefebvre C. Hemorrhagic infiltration of the aortopulmonary adventitia: A complication of acute aortic dissection. Eur J Radiol. 2016;85(1):239-247

19. Krizova A, Little D, Pollanen MS. Postmortem CT. gross and microscopic images of hemorrhage along the pulmonary artery sheath due to type A aortic dissection. Forensic Sci Med Pathol. 2015;11(3):455-9

20. Reid A, Stride P, Hunter J, Liew K, Wood T, Seleem M. Extensive bilateral extraluminal perivascular pulmonary haemorrhage associated with stanford type a aortic dissection. Case Rep Med. 2011;2011:681643

21. Makdisi G, Said SM, Schaff HV. Acute Aortic Dissection Extending Into the Lung. Ann Thorac Surg. 2015; 100(1):315-8

22. Sueyoshi E, Sakamoto I, Uetani M, Matsuoka Y, Suenaga E. CT findings of ruptured intramural hematoma of the aorta extending along the pulmonary artery. Cardiovasc Intervent Radiol. 2007;30(2):321-3

23. Sueyoshi E, Matsuoka Y, Sakamoto I, Uetani M. CT and clinical features of hemorrhage extending along the pulmonary artery due to ruptured aortic dissection. Eur Radiol. 2009;19(5):1166-74 
24. Charnsangavej $\mathrm{C}$. Occlusion of the right pulmonary artery by acute dissecting aortic aneurysm. AJR Am J Roentgenol. 1979;132(2):274-6

25. Lempel JK, Bauman JS, White CS. Aortopulmonary fistula in acute dissection: findings at unenhanced and enhanced computed tomographic imaging. J Thorac Imaging. 2012;27(6):W168-70

26. Nienaber CA, Eagle KA. Aortic dissection: new frontiers in diagnosis and management: Part I: from etiology to diagnostic strategies. Circulation. 2003;108(5):628-35

27. Muthu SK, Copley SJ. Case report: thickening of the peribronchovascular interstitium secondary to acute thoracic aortic dissection-chest radiograph and CT appearances. Clin Radiol. 2008;63(2):236-8

28. Cerna $M$, Kocher $M$, Thomas RP. Acute aorta, overview of acute $C T$ findings and endovascular treatment options. Biomed Pap Med Fac Univ Palacky Olomouc Czech Repub. 2017;161(1):14-23

29. Carey RM, Whelton PK. 2017 ACC/AHA Hypertension Guideline Writing Committee, Prevention, Detection, Evaluation, and Management of High Blood Pressure in Adults: Synopsis of the 2017 American College of Cardiology/American Heart Association Hypertension Guideline. Ann Intern Med. 2018;168(5):351-358

30. Downs JR, O'Malley PG. Management of dyslipidemia for cardiovascular disease risk reduction: synopsis of the 2014 U.S. Department of Veterans Affairs and U.S. Department of Defense clinical practice guideline. Ann Intern Med. 2015;163(4):291-7

31. Howard DP, Banerjee A, Fairhead JF, Perkins J, Silver LE, Rothwell PM; Oxford Vascular Study. Population-based study of incidence and outcome of acute aortic dissection and premorbid risk factor control: 10-year results from the Oxford Vascular Study. Circulation. 2013;127(20):2031-7

32. Dudzinski DM, Isselbacher EM. Diagnosis and Management of Thoracic Aortic Disease. Curr Cardiol Rep. 2015;17(12):106

33. Suzuki T, Mehta RH, Ince H, Nagai R, Sakomura Y, Weber F, Sumiyoshi T, Bossone E, Trimarchi S, Cooper JV, Smith DE, Isselbacher EM, Eagle KA, Nienaber CA; International Registry of Aortic Dissection. Clinical profiles and outcomes of acute type $B$ aortic dissection in the current era: lessons from the International Registry of Aortic Dissection (IRAD). Circulation. 2003;108 Suppl 1:II312-7

34. Muta $\mathrm{H}$, Ishii M, Maeno Y, Akagi T, Kato H. Quantitative evaluation of the changes in plasma concentrations of cardiac natriuretic peptide before and after transcatheter closure of atrial septal defect. Acta Paediatr. 2002;91(6):649-52

35. Sakakura K, Kubo N, Ako J, Ikeda N, Funayama H, Hirahara T, Sugawara Y, Yasu T, Kawakami M, Momomura S. Determinants of in-hospital death and rupture in patients with a Stanford B aortic dissection. Circ J. 2007;71(10):1521-4

36. Strayer RJ, Shearer PL, Hermann LK. Screening, evaluation, and early management of acute aortic dissection in the ED. Curr Cardiol Rev. 2012;8(2) 152-7

37. Chang CP, Liu JC, Liou YM, Chang SS, Chen JY. The role of false lumen size in prediction of inhospital complications after acute type B aortic dissection. J Am Coll Cardiol. 2008;52(14):1170-6 


\section{Tables}

Table 1 Gender composition of case group and control group

\begin{tabular}{ccccc}
\hline Gender & Total $(\mathbf{N = 5 4 )}$ & Case $(\mathbf{N}=18)$ & Control $(\mathbf{N}=36)$ & P value \\
\hline Male & 39 & 13 & 26 & 1.00 \\
Female & 15 & 5 & 10 & \\
& & & & \\
\hline
\end{tabular}

Table 2 Age composition of case group and control group

\begin{tabular}{lllll}
\hline Age & Total $(\mathrm{N}=54)$ & Case $(\mathrm{N}=18)$ & Control $(\mathrm{N}=36)$ & P value
\end{tabular}

\begin{tabular}{ccccc}
\hline Year & $60.0^{*}$ & 60.0 & 59.5 & 0.762 \\
& & & & \\
& $(54.0,67.0)^{\#}$ & $(55.0,70.0)$ & $(53.5,65.0)$ & \\
\hline
\end{tabular}

* Median value; \# (The first quartile value, the third quartile value)

Table 3 Clinical information of case group and control group

\begin{tabular}{|c|c|c|c|c|c|}
\hline Diseases & $\begin{array}{c}\text { Total } \\
(\mathrm{N}=54)\end{array}$ & $\begin{array}{l}\text { Case } \\
(\mathrm{N}=18)\end{array}$ & $\begin{array}{l}\text { Control } \\
(\mathrm{N}=36)\end{array}$ & $\begin{array}{c}\mathrm{X}^{2} \\
\text { value }\end{array}$ & $\begin{array}{c}P \\
\text { value }\end{array}$ \\
\hline Hypertension & $50(92.6 \%)$ & $16(88.9 \%)$ & $34(94.4 \%)$ & 1.607 & 0.205 \\
\hline Diabetes Mellitus & $10(18.5 \%)$ & $3(16.7 \%)$ & $7(19.4 \%)$ & 0.136 & 0.713 \\
\hline $\begin{array}{l}\text { Chronic cardiovascular and cerebrovascular } \\
\qquad \text { diseases }\end{array}$ & $17(31.5 \%)$ & $5(27.8 \%)$ & $12(33.3 \%)$ & 0.590 & 0.443 \\
\hline Chronic pulmonary disease & $6(11.1 \%)$ & $2(11.1 \%)$ & $4(11.1 \%)$ & - & 1.000 \\
\hline Moderate/moderate kidney damage & $\begin{array}{c}11 \\
(20.37 \%)\end{array}$ & $4(22.2 \%)$ & $7(19.4 \%)$ & 0.276 & 0.599 \\
\hline Connective tissue diseases & $7(13.0 \%)$ & $3(16.7 \%)$ & $4(11.1 \%)$ & 1.495 & 0.221 \\
\hline Peripheral vascular diseases & $11(20.4 \%)$ & $4(22.2 \%)$ & $7(19.4 \%)$ & 0.276 & 0.599 \\
\hline Mild liver damage & $5(9.3 \%)$ & $2(11.1 \%)$ & $3(8.3 \%)$ & 0.235 & 0.628 \\
\hline Cancer & $2(3.7 \%)$ & $1(5.6 \%)$ & $1(2.8 \%)$ & 0.974 & 0.324 \\
\hline
\end{tabular}


Table 4 Charlson comorbidity index (CCI) comparison between case group and control group

\begin{tabular}{ccccc}
\hline CCI & case group & control group & Z/c ${ }^{2}$ value & P value \\
\hline Median & $2^{*}(1,3)^{\#}$ & $1(1,1.5)^{*}$ & 1.062 & 0.043 \\
0 & $3(16.67)$ & $8(22.2)$ & 39.994 & $<0.001$ \\
1 & $5(27.78)$ & $19(52.78)$ & & \\
2 & $4(22.22)$ & $6(16.67)$ & & \\
3 & $6(33.33)$ & $1(2.78)$ & & \\
4 & $0(0.00)$ & $2(5.56)$ & & \\
\hline
\end{tabular}

* Median value; \# (The first quartile value, the third quartile value)

Table 5 Clinical symptoms comparison between case group and control group

\begin{tabular}{ccccc}
\hline Clinical symptom & Total $(\mathrm{N}=54)$ & Case $(\mathrm{N}=18)$ & Control $(\mathbf{N}=36)$ & P value \\
\hline Chest pain & $53(98.15 \%)$ & $18(100 \%)$ & $35(97.22 \%)$ & \\
Syncope & $5(9.26 \%)$ & $2(11.11 \%)$ & $3(8.33 \%)$ & \\
Sudden breathing difficulty & $3(5.56 \%)$ & $2(11.11 \%)$ & $1(2.78 \%)$ & 0.320 \\
Hemoptysis or blood stasis & $2(3.70 \%)$ & $1(5.56 \%)$ & $1(2.78 \%)$ & \\
Cough & $2(3.70 \%)$ & $1(5.56 \%)$ & $1(2.78 \%)$ & \\
Shortness of breath & $5(9.26 \%)$ & $2(11.11 \%)$ & $3(8.33 \%)$ & \\
\hline
\end{tabular}

Table 6 clinical signs comparison between case group and control group

\begin{tabular}{ccccc}
\hline Clinical signs & Total $(\mathbf{N}=54)$ & Case $(\mathbf{N}=18)$ & Control $(\mathbf{N}=36)$ & P value \\
\hline Tachycardia & $5(9.26 \%)$ & $2(11.11 \%)$ & $3(8.33 \%)$ & \\
Blood pressure drop & $1(2.78 \%)$ & $0(0.00 \%)$ & $1(2.78 \%)$ & \\
Myocardial infarction or ischemia & $4(7.41 \%)$ & $1(5.56 \%)$ & $3(8.33 \%)$ & 0.303 \\
Renal Failure & $8(14.81 \%)$ & $3(16.67 \%)$ & $5(13.89 \%)$ & \\
Abnormal liver function & $2(3.70 \%)$ & $1(5.56 \%)$ & $1(2.78 \%)$ & \\
\hline
\end{tabular}


Table 7 MDCT features comparison between case group and control group

\begin{tabular}{|c|c|c|c|c|}
\hline MDCT features & Subgroup & Case $(\mathrm{N}=18)$ & Control $(\mathrm{N}=36)$ & $\begin{array}{c}\mathrm{P} \\
\text { value }\end{array}$ \\
\hline $\begin{array}{l}\text { Maximum diameter of ascending } \\
\text { aorta }(\mathrm{mm})\end{array}$ & - & $\begin{array}{c}50.5^{*}(44.0 \\
68.0)^{\#}\end{array}$ & $\begin{array}{c}49.0^{*}(38.0 \\
85.0)\end{array}$ & 0.321 \\
\hline \multirow[t]{3}{*}{ Aortic dissection range } & Ascending aorta & $2(11.11)$ & $6(16.67)$ & 0.367 \\
\hline & Thoracic aorta & $5(27.78)$ & $8(22.22)$ & \\
\hline & Lower abdomen aorta & $11(61.11)$ & $22(61.11)$ & \\
\hline \multirow[t]{4}{*}{ Main branch of aorta } & No & $5(27.78)$ & $14(38.89)$ & $<0.001$ \\
\hline & Branches of the & $6(33.33)$ & $3(8.33)$ & \\
\hline & brachiocephalus & & & \\
\hline & Ventral branch & 7 (38.89) & 19 (52.78) & \\
\hline \multirow[t]{3}{*}{ Pleural effusion/blood } & No & $9(50.00)$ & $16(44.44)$ & 0.204 \\
\hline & Pleural blood & $0(0.00)$ & $1(2.78)$ & \\
\hline & Pleural effusion & $9(50.00)$ & 19 (52.78) & \\
\hline \multirow[t]{3}{*}{ Pericardial effusion/blood } & No & $2(11.11)$ & $5(13.89)$ & 0.268 \\
\hline & Pericardial blood & $12(66.67)$ & $20(55.56)$ & \\
\hline & Pericardial effusion & $4(22.22)$ & $11(30.55)$ & \\
\hline
\end{tabular}

* Median value; \# (The first quartile value, the third quartile value)

Table 8 Single-factor conditional logistic regression analysis of MDCT features and HPS 


\begin{tabular}{|c|c|c|c|c|c|c|c|c|}
\hline Item & Subgroup & B & S.E, & Walds & $\mathrm{df}$ & $\mathrm{p}$ & OR & $95 \% \mathrm{CI}$ \\
\hline Age & - & 0.006 & 0.027 & 0.054 & 1 & 0.817 & 1.006 & $\begin{array}{l}0.954- \\
1.061\end{array}$ \\
\hline Gender & - & 0.000 & 0.645 & 0.000 & 1 & 1.000 & 1.000 & $\begin{array}{l}0.283- \\
3.537\end{array}$ \\
\hline CCI & - & 0.499 & 0.282 & 3.119 & 1 & $0.077^{*}$ & 1.647 & $\begin{array}{l}0.947- \\
2.864\end{array}$ \\
\hline Hypertension & - & -0.169 & 0.706 & 0.057 & 1 & 0.811 & 0.845 & $\begin{array}{l}0.212- \\
3.372\end{array}$ \\
\hline $\begin{array}{l}\text { Maximum diameter of } \\
\text { ascending aorta ( } \mathrm{mm})\end{array}$ & - & 0.005 & 0.032 & 0.023 & 1 & 0.879 & 1.005 & $\begin{array}{l}0.943- \\
1.070\end{array}$ \\
\hline \multirow[t]{2}{*}{ Main branch of aorta } & Brachiocephalus & 1.838 & 0.830 & 4.910 & 1 & $0.027^{*}$ & 6.286 & $\begin{array}{l}1.236- \\
31.956\end{array}$ \\
\hline & No & 0.357 & 0.692 & 0.266 & 1 & 0.606 & 1.429 & $\begin{array}{l}0.368- \\
5.548\end{array}$ \\
\hline \multirow[t]{2}{*}{ Aortic dissection range } & Ascending aorta & 1.504 & 1.208 & 1.551 & 1 & 0.213 & 4.499 & $\begin{array}{l}0.422- \\
47.979\end{array}$ \\
\hline & Thoracic aorta & 1.099 & 1.141 & 0.926 & 1 & 0.336 & 3.000 & $\begin{array}{l}0.320- \\
28.098\end{array}$ \\
\hline \multirow[t]{2}{*}{ Pleural effusion/blood } & Pleural effusion & -0.172 & 0.581 & 0.088 & 1 & 0.767 & 0.842 & $\begin{array}{l}0.270- \\
2.629\end{array}$ \\
\hline & Pleural blood & -12.79 & 797.1 & 0.000 & 1 & 0.987 & $<0.001$ & $\begin{array}{l}<0.001- \\
>999.999\end{array}$ \\
\hline \multirow[t]{2}{*}{ Pericardial effusion/blood } & $\begin{array}{l}\text { Pericardial } \\
\text { effusion }\end{array}$ & 0.598 & 1.241 & 0.232 & 1 & 0.630 & 3.250 & $\begin{array}{l}0.340- \\
31.073\end{array}$ \\
\hline & $\begin{array}{l}\text { Pericardial } \\
\text { blood }\end{array}$ & 1.179 & 1.152 & 1.047 & 1 & 0.306 & 1.818 & $\begin{array}{l}0.160- \\
20.713\end{array}$ \\
\hline
\end{tabular}

Table 9 Single-factor conditional logistic regression analysis of MDCT features and HPS

\begin{tabular}{cccccccc}
\hline Item & B & S.E, & Walds & df & P & OR & 95\%CI \\
\hline Age & -0.018 & 0.033 & 0.280 & 1 & 0.597 & 0.982 & $0.920-1.049$ \\
Gender & 0.362 & 0.846 & 0.183 & 1 & 0.669 & 1.436 & $0.274-7.536$ \\
CCI & 0.591 & 0.318 & 3.461 & 1 & 0.063 & 1.805 & $0.969-3.364$ \\
Main branch of aorta & - & - & 5.038 & 2 & 0.081 & - & - \\
Without main branch of aorta & 0.658 & 0.763 & 0.744 & 1 & 0.388 & 1.932 & $0.433-8.621$ \\
& & & & & & & \\
Branches of the brachiocephalus & 2.038 & 0.909 & 5.030 & 1 & $0.025^{\#}$ & $7.02^{*}$ & $1.28-38.62$ \\
\hline
\end{tabular}


\# After adjusting for CCI, multivariate analysis showed that the branch of brachiocephalus in case group was different with that in the control group.* The risk of HPS is greater in the involvement of branches of the brachiocephalus than that in ventral branch $(\mathrm{OR}=7.02)$.

\section{Supplementary Files}

This is a list of supplementary files associated with this preprint. Click to download.

- supplement1.docx 